\title{
CardioVascular and Interventional Radiology (CVIR) Welcomes Our New Editors, Dr. Aghiad Al-Kutoubi, Dr. William Clark, Dr. Bien-Soo Tan, and Dr. Chang Jin Yoon
}

\author{
D. Vorwerk
}

(C) Springer Science+Business Media, LLC and the Cardiovascular and Interventional Radiological Society of Europe (CIRSE) 2011

On behalf of the CVIR Editorial Board, we are happy to welcome Dr. Al-Kutoubi as our new Editor for the Middle East, Dr. William Clark as our new Editor for Australia, Dr. Bien-Soo Tan as our new Editor for Southeast Asia, and Dr. Chang Jin Yoon as our new Editor in Korea for CVIR.

Dr. Al-Kutoubi is currently Professor and Chairman of the Department of Radiology at the American University of Beirut Medical Center. His many research articles, Abstracts, transactions and communications in international conferences have been published in a large variety of medical journals, including CVIR. In addition, he has been awarded honors for two of his many written book chapters. Presently, Dr. Al-Kutoubi is a member of numerous academic and medical committees both in the UK and at the AUB; he has been a visiting professor and invited faculty in prestigious facilities worldwide; he was elected Vice President of the Arab Board in Radiodiagnosis and Medical Imaging in 2002; he is a current Fellow of the Royal College of Radiologists, a Founder-Member of the Arab Medical Association in the UK and Ireland, and an active member in many prestigious societies including the Royal Society of Medicine, BSIR, and CIRSE.

Dr. Clark is currently Director of Angiography and Interventional Radiology at St. George Private Hospital in Kogarah in New South Wales, and he is the current President of the Interventional Radiology Society of Australasia (IRSA). Additionally, Dr. Clark is a committee member of the Australian Day Surgery Advisory Committee and an honorary member of the Hong Kong Society of Interventional Radiology.
Dr. Bien-Soo Tan is currently Senior Consultant and immediate past Head of the Department of Diagnostic Radiology at Singapore General Hospital. He is a prolific author of published papers, book chapters, presentations and lectures, and has been a participating investigator in many funded research projects. Dr. Tan's numerous current appointments and memberships include Adjunct Associate Professor at the Duke-NUS Graduate Medical School; Clinical Associate Professor at the Yong Loo Lin School of Medicine, National University of Singapore; Immediate Past President of the College of Radiologists, Singapore; Fellow of the Royal College of Radiologists since 1992; Fellow of the Society of Interventional Radiology since 2005, and Member of the Singapore Radiological Society since 1988. In 2009, Dr. Tan was awarded the Star Award, Excellent Service Award (EXSA) and in 2008 he was awarded both the Silver Award, Excellent Service Award (EXSA) and the SGH Service Quality Award (Service with a Heart).

Dr. Chang Jin Yoon is currently Associate Professor of the Department of Radiology at Seoul National University Bundang Hospital. Dr. Yoon has published a significant number of published papers, book chapters, and presentations, and has received a Certificate of Merit Award from RSNA, a Cum Laude Award from CIRSE, and an Award for Outstanding International Publication from the Korean Radiological Society.

We are proud to welcome Drs. Al-Kutoubi, Clark, Tan, and Yoon as highly recognized specialists to our CVIR team. Congratulations, and welcome aboard! 